\title{
EPIDEMIOLOGY OF SPINAL TRAUMA SURGICALLY TREATED AT THE UNICAMP HOSPITAL DAS CLÍNICAS
}

\author{
EPIDEMIOLOGIA DO TRAUMATISMO RAQUIMEDULAR TRATADO CIRURGICAMENTE \\ NO HOSPITAL DAS CLIINICAS DA UNICAMP
}

\section{EPIDEMIOLOGÍA DEL TRAUMATISMO RAQUIMEDULAR TRATADO QUIRÚRGICAMENTE EN EL HOSPITAL DAS CLÍNICAS DE UNICAMP}

Otávio Turolo da Silva' ${ }^{1}$ Enrico Ghizoni ${ }^{1}$, Helder Tedeschi ${ }^{1}$, Andrei Fernandes Joaquim ${ }^{1}$

1. Department of Neurology, division of Neurosurgery of Unicamp - Campinas, SP, Brazil.

\begin{abstract}
Objective: To report the epidemiological profile of patients operated for treatment of spinal trauma in the UNICAMP Hospital das Clínicas. Methods: Patients older than 14 years with spinal trauma operated in the service from 2012 to 2017 with complete radiological and clinical data were evaluated. Results: A total of 143 patients were included, 120 men and 23 women, with a mean age of 37.8 years. Falls from height (32\%), motorcycle (26\%) and car accidents (24\%) were the most common trauma mechanisms. The most affected vertebral level was C6 (11\%) and most patients (55\%) had some neurological deficits. The overall postoperative complication rate was $23 \%$. Conclusions: Spinal trauma has a high socioeconomic impact due to its high morbidity and mortality, and it is necessary to study its epidemiology for the development of public policies for prevention and treatment financing. Level of Evidence: III. Type of study: Retrospective study.
\end{abstract}

Keywords: Spinal cord injury; Spine; Surgery; Treatment; Epidemiology.

\section{RESUMO}

Objetivo: Reportar o perfil epidemiológico dos pacientes operados para tratamento do TRM no Hospital das Clínicas da UNICAMP. Métodos: Pacientes maiores de 14 anos, com TRM operados no serviço no período de 2012 a 2017, com dados radiológicos e clínicos completos foram avaliados. Resultados: 143 pacientes foram incluídos, sendo 120 homens e 23 mulheres, com idade média de 37, 8 anos. Quedas (32\%), acidentes de motocicletas (26\%) e de automóveis (24\%) foram os mecanismos de trauma mais comuns. O nível vertebral mais acometido foi o de C6 (11\%) e a maioria dos pacientes tinha algum déficit neurológico (55\%). A taxa geral de complicação pós-operatória foi de 23\%. Conclusões: O Traumatismo Raquimedular (TRM) tem alto impacto sócio-econômico devido sua alta morbi-mortalidade, sendo que é necessário estudar sua epidemiologia para o desenvolvimento de políticas públicas de prevenção e financiamento do tratamento do mesmo. Nível de evidência III. Tipo de estudo: Estudo Retrospectivo.

Descritores: Traumatismos da medula espinal; Coluna vertebral; Cirurgia; Tratamento; Epidemiologia.

\section{RESUMEN}

Objetivo: Describir el perfil epidemiológico de los pacientes operados para tratamiento quirúrgico debido a TRM en el Hospital das Clínicas de UNICAMP. Métodos: Se evaluaron pacientes mayores de 14 años con TRM operados en el servicio de 2012 a 2017 , con datos radiológicos y clínicos completos. Resultados: Fueron incluidos 143 pacientes, siendo 120 hombres y 23 mujeres, con una edad promedio de 37,8 años. Caídas de altura (32\%), accidentes de motocicleta (26\%) y accidentes de autos (24\%) fueron los mecanismos de trauma más comunes. El nivel vertebral más afectado fue C6 (11\%) y la mayoría de los pacientes tenía algún déficit neurológico (55\%). La tasa global de complicaciones postoperatorias fue del 23\%. Conclusiones: El TRM tiene un alto impacto socioeconómico debido a su alta morbilidad y mortalidad; por lo tanto es necesario estudiar su epidemiología para el desarrollo de políticas públicas de prevención y financiamiento del tratamiento. Nivel de evidencia: III. Tipo de Estudio: Estudio retrospectivo.

Descriptores: Traumatismos de la medula espinal; Columna vertebral; Cirugía; Tratamiento; Epidemiología.

\section{INTRODUCTION}

Spinal trauma comprises spine lesions, with or without involvement of the spinal cord, as well as associated disc ligament lesions, secondary to any traumatic event, whether or not the result of direct impact to the spine. ${ }^{1}$ Because of the relevance of spinal cord injuries in terms of morbidity and mortality, new care protocols are created to facilitate and improve patient treatment. ${ }^{2}$

In the United States, it is estimated that around 13,000 patients are victims of traumatic spinal cord injury, with a total cumulative cost of $\$ 1.1$ to $\$ 4.6$ million per patient, ${ }^{3}$ considering hospital expenses, work days lost, and the burden on social security. In Brazil, there are an estimated six to eight thousand new cases per year. However, epidemiological studies are scarce at the national level. ${ }^{4}$ Traumatic injuries of the spine can be categorized by the level of involvement: craniovertebral junction, subaxial cervical spine, thoracolumbar spine, and sacral spine..$^{5-6}$ Each segment should be evaluated separately, taking into account the differences and particularities between them. 
During preadmission treatment, the rescue team should ensure the use of a cervical collar and decompressive mobilization care. ${ }^{6}$ Following admission, all patients with spinal trauma should undergo an emergency evaluation, which cannot be postponed. ${ }^{7}$

\section{METHODS}

Patients who underwent surgery for spinal trauma in the Neurosurgery unit of Unicamp from 2012 to 2017 were evaluated. All the patients were operated on by the same surgeon (AFJ). Postoperative outpatient follow-up was generally performed at one month, three months, six months, and then annually. Vertebral lesions of any segment were included and all patients were older than 14 years of age. Cases operated outside of the service or with incomplete clinical and radiographic data were excluded from the study.

Through a review of the medical records, age, sex, date of accident, trauma mechanism, injury level, American Spine Injury Association Impairment Score (AIS) ${ }^{8}$ (Table 1), and postoperative complications data were collected. For statistical analysis, we used STATA MP version 13 software (StataCorp ${ }^{\circledR}$ ).

For the literature review, a search of the Pubmed/MEDLINE database was conducted using the MeSH descriptors: "Spine trauma" OR "Spine" OR "trauma" AND "surgery". We found 249,127 articles. Only articles that fit the theme, that were written in English, and that had complete text were evaluated, for a total of 415 articles. The abstracts of these were read and 25 articles were selected to be used in our study discussion.

This study was approved by the Institutional Review Board of Unicamp as CAAE - 17337313.7.0000.5404. Because it was a study based in the review of medical records, the ICF requirement was waived.

Table 1. Neurological grading according to the AIS (ASIA Impairment Scale). ${ }^{8}$

\begin{tabular}{c|c}
\hline A & Full neurological deficit, including the sacral segment. \\
\hline B & Full motor deficit, feeling preserved (sacral segments present). \\
\hline C & Partial motor deficit, loss of $>50 \%$ (or $<3 / 5$ ). \\
\hline D & Partial motor deficit, loss of $<50 \%$ (or $>3 / 5$ ). \\
\hline E & $\begin{array}{c}\text { No deficit, however presented a temporary } \\
\text { deficit, including nerve root deficit. }\end{array}$ \\
\hline
\end{tabular}

\section{RESULTS}

A total of 143 patients were evaluated, all of whom had undergone surgery for spinal trauma during the period from 2012 to 2017 . Of the 143 patients, 25 (17\%) were operated on in 2012, 21 914\%) in 2013, 35 (24\%) in 2014, 33 923\%) in 2015, 27 (18\%) in 2016, and 2 91\%) in 2017. The distribution by sex was 120 men (84\%) and 23 women (16\%). The average age was 37.8 years, ranging from 16 to 82 years of age.

The main trauma mechanism was falls in 47 cases (32\%), followed by motorcycle accidents in 38 cases (26\%), and automobile accidents in 36 cases (32\%), with these three causes corresponding to of the total traumatisms. Other less common causes were seven cases $(4 \%)$ of diving in shallow water, seven cases (4\%) of being run over, five $(3 \%)$ of explosions, one $(0.7 \%)$ of a kick by a domestic animal, and one $(0.7 \%)$ case of direct physical aggression.

In relation to neurological deficit according to the AIS classification at the time of hospital admission, 28 patients (20\%) were rated AIS A or with full deficit, seven patients (5\%) AIS B, 30 patients (21\%) AIS C, 13 patients (9\%) AIS D, and 65 patients (45\%) as neurologically intact (Figure 1).

In terms of the level of the injury (the vertebra fractured), we had 19 fractures of the craniovertebral junction (9.33\%), 75 fractures of the subaxial cervical spine (C3 to C7) (36\%), and 110 fractures of the thoracolumbar spine (53.9\%), 46 of which were from T1 to T10 (22.5\%), 49 from T11 to L2 (24\%), and 15 from L3 to L5 (7.3\%). In total, we had an average of 1.4 fractures per patient (Figure 2). No sacral fracture was treated surgically in this case series.

The postoperative complication rate was 23\% (33 cases), the main complication being local infections with an overall rate of $11.9 \%$

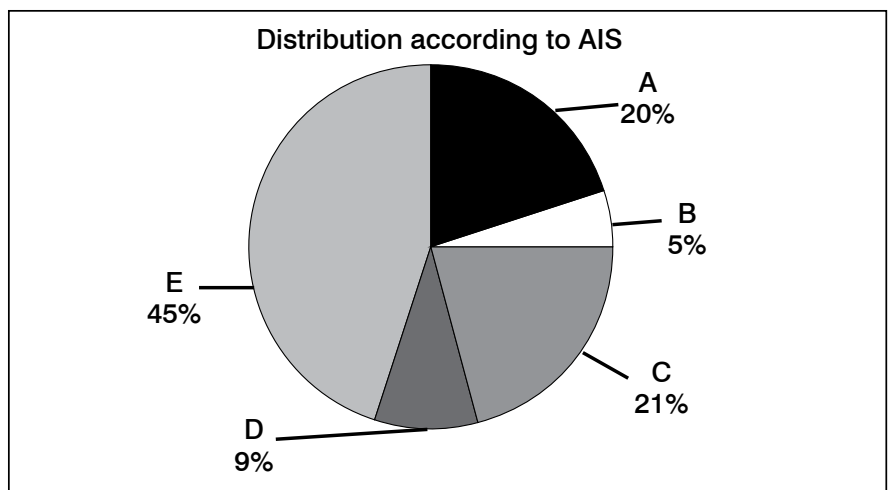

Figure 1. Shows the distribution of the 143 patients in relation to neurological damage according to the AIS. Most patients (45\%) had no neurological deficits in the initial evaluation (E), followed by $35 \%$ with partial deficits ( $D, C$, and $B$ ), and $20 \%$ with full sensory and motor deficit (A).

\section{Distrubution according to the spinal injured level}

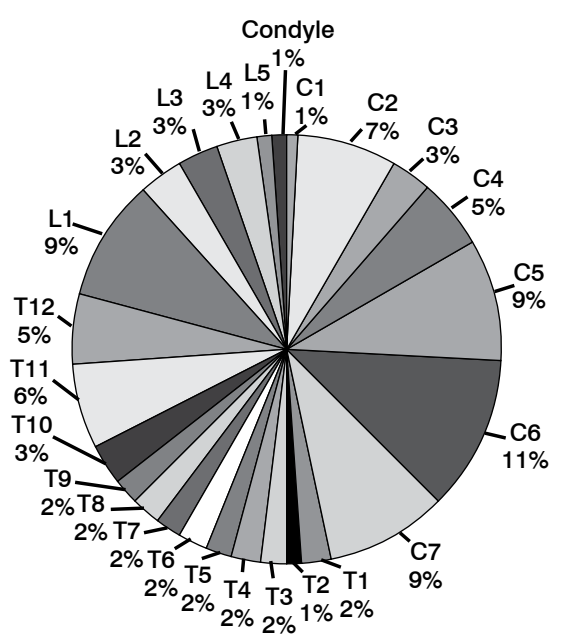

Figure 2. The figure shows the distribution of the 204 fractures found in these patients. Most of the fractures (53.9\%) were in the thoracolumbar region, L1 being the most affected level (9\%) in this segment. However, of the total number of fractures, those of C6 were the most predominant at $11 \%$, even though subaxial fractures accounted for $36 \%$ of all the fractures.

(17 cases). In total, 7\% (10 cases) had infections of the surgical wound, $1.4 \%$ (two cases) contracted meningitis, and 4.9\% (seven cases) developed pneumonia. The complication rate for the instrumentation breakage or repositioning of screws/rods was 3.5\% (five cases reoperated). Cerebrospinal fluid fistulas requiring reoperation occurred in two cases $(1.4 \%)$. The postoperative mortality rate was $2.1 \%$ (three cases).

\section{Results by Segment}

\section{Craniovertebral Junction (O-C1-C2)}

There were 16 patients who underwent surgery for fractures of the craniovertebral junction, 13 men, and three women with an average age of 35.8 years. The primary injury mechanism was automobile accidents in seven cases (43.7\%), motorcycle accidents in four cases (25\%), and falls from heights in four cases $(25 \%)$.

Most of the patients (13 cases, $81.2 \%$ ) did not have neurological damage. There was one case $(6.2 \%)$ of AIS D and two cases (12.5\%) of AIS C. There were two condyle fractures (10\%), two C1 fractures (10\%), and 15 C2 fractures (80\%).

There were postoperative complications in only one case (6.2\%), in which there was a dural lesion and meningitis occurred, treated successfully with antibiotics. There were no deaths in this segment. 


\section{Subaxial Cervical (C3-C6)}

There were 44 patients who underwent surgery for fractures of the subaxial cervical spine, of whom 41 were men $(93.1 \%)$ and 3 women (6.8\%), with an average age of 40.9 years. The main injury mechanisms were automobile accidents with 15 cases (34\%), falls from height with 13 cases (29.5\%), motorcycle accidents with seven cases $(15.9 \%)$, and diving in shallow water with six cases $(13.6 \%)$.

Most of them had neurological deficit, 10 with full spinal cord injury (AIS A, 22.7\%), three with AIS B (6.8\%), 16 with AIS C (36.6\%), six with AIS D (13.6\%), and only nine without neurological deficit (20.4\%). The most frequent injury level was C6 with 22 cases (29\%), followed by C5 with 19 cases (25.3\%), C7 with 18 cases (24\%), C4 with 10 cases $(13.3 \%)$, and C3 with six cases (8\%).

Eleven patients had postoperative complications (25\%), the main one being pneumonia or ventilatory difficulties in five cases (11.3\%), followed by systemic infectious complications with four patients (9\%), two of whom died from sepsis in the postoperative period (4.5\%).

\section{Thoracolumbar (T1-L5)}

There were 83 patients in this series with thoracolumbar trauma who underwent surgery. In total, there were 66 men (79.5\%) and 17 women (20.4\%), with an average age of 36.6 years. The main injury mechanism was falls, at 30 cases $(36.1 \%)$, followed by motorcycle accidents at 27 cases (32.5\%), and automobile accidents at 14 cases $(16.8 \%)$.

Slightly over half of the patients had no neurological deficits (51.8\%), followed by six AIS D patients (7.3\%), 12 AIS C (14.4\%), four AIS B (4.8\%), and 18 AIS A patients (21.6\%). The level most impacted by injuries was L1 with 19 cases $(17.2 \%)$, followed by T11 with 13 cases $(11.8 \%), T 12$ with 10 cases $(9 \%), L 2$ and $L 4$ with seven cases each (6.3\% each), L3 with six cases (5.4\%), T1, T5, T7, and T8 with five cases each (4.5\% each), T3, T4, T6, and T9 with four cases each (3.6\% each), T2 with three cases (2.7\%), and L5 with two cases (1.8\%).

Twenty patients had postoperative complications (24\%), the main one (13 cases, $15.6 \%$ ) being infection. Of these, three cases $(3.6 \%)$ were of sepsis and one case was meningitis (1.2\%). Five cases had problems with the instrumentation and reoperation was required (6\%). None of the patients with thoracolumbar trauma died during postoperative hospitalization.

\section{Sacral (S1-Coccyx)}

No sacral fractures were treated surgically in this series.

\section{DISCUSSION}

It is believed that the worldwide prevalence of spinal trauma is between 236 and 4187 cases per million inhabitants, ${ }^{9}$ although these data may be underestimated due to a lack of reporting. However, the prevalence of spinal trauma in men is around three to four times greater than in women, ${ }^{10}$ similar to the findings in our series (84\% vs. $16 \%$ ).

The principal causal mechanisms of spinal trauma in several studies were falls, land transportation accidents (car, motorbike), recreation (sports and leisure), and aggression. ${ }^{11}$ Although this agrees with the data obtained in our series, the lack of adequate information about the trauma mechanism in epidemiological studies and the fact that the information available is not always exact (ex. a fall during a recreational activity versus a fall from a height), underestimating or overestimating the data presented.

There are two peaks of incidence, one in young adults from 15 to 29 years of age, more related to traffic accidents, and a second after 65 years of age, usually related to falls from a standing position. ${ }^{12}$ Paradoxically, there is a higher incidence of spinal trauma in developed countries. However, this could be secondary to underreporting of spinal trauma in underdeveloped countries, as well as to the lower number of published epidemiological studies.

The evaluation of a patient with spinal trauma should follow the criteria proposed by the Advanced Trauma Life Support (ATLS). ${ }^{13}$ Most patients with spinal trauma are victims of high kinetic energy traumas. In our series, land transportation vehicle accidents corresponded to almost $50 \%$ of all trauma mechanisms, with a high probability of lesions to other organs. Adequate ventilation and oxygenation support must be ensured and hemodynamic stability achieved before the secondary assessment of the spine surgeon.

During the secondary evaluation of a polytraumatized patient, the exam of choice for assessing the integrity of the spine is computed tomography (CT) with three-dimensional reconstruction. The use of simple radiographs was widely used for a long time. However, we know that for some injuries, especially those of the craniovertebral junction (CVJ), such as condyle fractures, simple radiography has lower sensitivity and specificity than CT in detecting fractures. ${ }^{14}$

Over time, numerous ways of classifying spine fractures through imaging exams have been proposed to facilitate their treatment and understand their severity. Thus, classification by the morphology of the injury is well accepted.

Fractures can be classified as type A (compression/burst), secondary to compressive axial overload, type B (injuries with lesion of the tension band of the anterior or posterior spine), and type $\mathrm{C}$ (rotation/translation), secondary to translational and rotational loads. ${ }^{15}$ Classically, type A fractures (compression/burst) tend to be stable and types $B$ and $C$ classified as unstable, each with its own particularities. ${ }^{16}$

The new morphological classifications based on these mechanisms proposed by AOSpine, ${ }^{15-17}$ both of the subaxial cervical and thoracolumbar spines, were assessed by the authors and were shown to be reproducible and safe in the series evaluated. ${ }^{18-19}$

Additionally, fractures can usually be classified as either stable or unstable. The concept of stability was defined by White and Panjabi ${ }^{20}$ as the capacity of the spine to maintain alignment under physiological loads, without pain or neurological injury.

However, the previously proposed concept of stability is subjective, causing divergence in the conduct of the spine surgeons. To standardize the conducts, the Spinal Trauma Study Group proposed algorithms to determine objective instability criteria based on the morphology of the fracture, the neurological status of the patient, and on the integrity of the posterior ligament complex. They suggested the SLICS ${ }^{21}$ and the TLICS ${ }^{22}$ (Tables 2 and 3). In both scores, patients with fewer than four points are treated non-surgically, patients with more than four points are treated surgically, and patients with four points may be treated surgically or non-surgically depending on other variables, such as comorbidities, the experience of the surgeon, bone or metabolic diseases, etc.

The exception is in the craniovertebral junction (CVJ) that has specific classification for each type of lesion, whether of the condyle, of $\mathrm{C} 1$, or of $\mathrm{C} 2 .{ }^{23-24}$ Joaquim et al. ${ }^{23-24}$ proposed instability criteria for the CVJ to guide surgical conduct (Figure 3). Patients with suspected ligament injury (misalignment of the vertebrae, increase in

Table 2. Subaxial Cervical Spine Injury Classification System (SLICS). Adapted from Patel et al. ${ }^{21}$

\begin{tabular}{c|c}
\hline Morphology & Points \\
\hline Without changes & 0 \\
\hline Compression (A) & 1 \\
\hline Burst (A +1) & +1 \\
\hline Distraction (B) & 3 \\
\hline Translation/Rotation (C) & 4 \\
\hline Posterior ligament complex integrity & 0 \\
\hline Intact & 1 \\
\hline Undetermined & 2 \\
\hline Ruptured & 0 \\
\hline Neurological status & 1 \\
\hline Intact & 2 \\
\hline Radicular lesion & 3 \\
\hline Full deficit & +1 \\
\hline Partial deficit &
\end{tabular}


Table 3. Thoracolumbar Injury Classification System and Injury Severity Score (TLICS). Adapted from Patel et al. ${ }^{22}$

\begin{tabular}{c|c}
\hline Morphology & Points \\
\hline Without changes & 0 \\
\hline Compression (A) & 1 \\
\hline Burst (A +1) & +1 \\
\hline Translation/Rotation (C) & 3 \\
\hline Distraction (B) & 4 \\
\hline Posterior ligament complex integrity & 0 \\
\hline Intact & 2 \\
\hline Undetermined & 3 \\
\hline Ruptured & 0 \\
\hline Neurological status & 2 \\
\hline Intact & 2 \\
\hline Radicular lesion & 3 \\
\hline Full deficit & 3 \\
\hline Partial deficit & \\
\hline Cauda Equina Syndrome &
\end{tabular}

the atlantodental interval, articular luxation, etc.) may be potentially unstable, requiring stabilization. In general, fractures of the CVJ are handled conservatively, however, attention should be given to Anderson and D'Alonzo ${ }^{25}$ type two fractures of the odontoid process, which may present late instability and neural compression.

\section{CONCLUSIONS}

Spinal cord injury is a complex pathology and its treatment is full of nuances. It should be treated as a neurological emergency

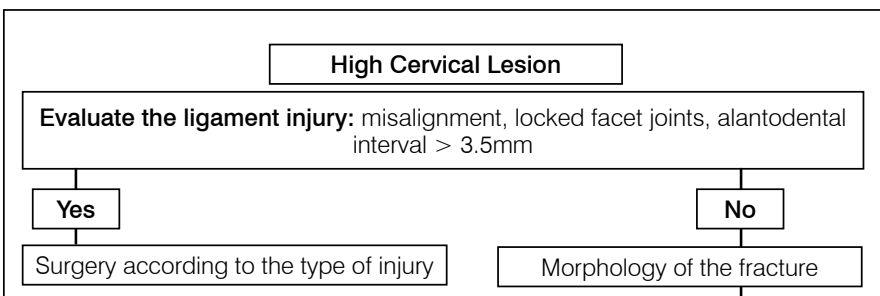

Fractures of the condyle and $\mathbf{C} 1$ - initially conservative with a Philadelphia cervical collar

Fractures of $\mathbf{C 2}$ - initially conservative:

Surgery if - type 2 odontoid fracture in patient $>50$ years of age, deviation $>5 \mathrm{~mm}$ or comminution

Surgery if - fractures that do not consolidate in control image exams

Figure 3. Flowchart for the evaluation of the instability of high cervical lesions. Adapted from Joaquim et al..$^{23-24}$

due to the imminent risk of serious and permanent deficit, which causes high morbidity and mortality rates. Epidemiological knowledge is fundamental to planning preventive measures and to directing treatment resources.

\section{ACKNOWLEDGEMENTS}

We thank the Brazilian Spine Society for the opportunity to publicize our national technical-scientific production.

All authors declare no potential conflict of interest related to this article.

CONTRIBUTION OF THE AUTHORS: Each author made significant individual contributions to this manuscript. Patient data was evaluated by AFJ (0000-0003-2645-0483)* and OTS (0000-0001-6015-0199)*. The article was written by) OTS and AFJ. The final review was done by AFJ, HT(00000003-3347-3886)*, and EG (0000-0001-8684-1780)* . ${ }^{\star}$ ORCID (Open Researcher and Contributor ID).

\section{REFERENCES}

1. Joaquim AF, Patel AA. Thoracolumbar spine trauma: Evaluation and surgical decision-making. J Craniovertebral Junction Spine. 2013:4(1):3-9.

2. Kim BG, Dan JM, Shin DE. Treatment of thoracolumbar fracture. Asian Spine J.2015;9(1):133-46.

3. Azhari S, Azimi P, Shahzadi S, Mohammadi HR, Khayat Kashani HR. Decision-Making Process in Patients with Thoracolumbar and Lumbar Burst Fractures with Thoracolumbar Injury Severity and Classification Score Less than Four. Asian Spine J. 2016;10(1):136-42.

4. Ovalle F A T REC, Balbuena F R Incidence and functional evolution of traumatic injuries of the spine. Coluna/Columna 2014;13(3):223-7.

5. Panjabi MM, White AA 3rd. Basic biomechanics of the spine. Neurosurgery. 1980;7(1):76-93.

6. Ramasamy A, Midwinter M, Mahoney P, Clasper J. Learning the lessons from conflict: pre-hospital cervical spine stabilisation following ballistic neck trauma. Injury. 2009;40(12):1342-5.

7. Schmidt OI, Gahr RH, Gosse A, Heyde CE. ATLS(R) and damage control in spine trauma. World J Emerg Surgery: WJES. 2009;4:9

8. Roberts TT, Leonard GR, Cepela DJ. Classifications In Brief: American Spinal Injury Association (ASIA) Impairment Scale. Clin Orthop Relat Res. 2017;475(5):1499-504.

9. Lee BB, Cripps RA, Fitzharris M, Wing PC. The global map for traumatic spinal cord injury epidemiology: update 2011, global incidence rate. Spinal Cord. 2014;52(2):110-6.

10. Devivo MJ. Epidemiology of traumatic spinal cord injury: trends and future implications. Spinal Cord. 2012:50(5):365-72.

11. Witiw CD, Fehlings MG. Acute Spinal Cord Injury. J Spinal Disord Tech. 2015;28(6):202-10.

12. Van den Berg ME, Castellote JM, Mahillo-Fernandez I, de Pedro-Cuesta J. Incidence of nontraumatic spinal cord injury: a Spanish cohort study (1972-2008). Arch Phys Med Rehabili. 2012;93(2):325-31.

13. Hall AB, Boecker FS, Shipp JM, Hanseman D. Advanced Trauma Life Support Time Standards. Mil mMed. 2017;182(3):e1588-90.

14. Tehranzadeh J, Bonk RT, Ansari A, Mesgarzadeh M. Efficacy of limited CT for nonvisualized lower cervical spine in patients with blunt trauma. Skeletal Radiol. 1994;23(5):349-52.

15. Vaccaro AR, Oner C, Kepler CK, Dvorak M, Schnake K, Bellabarba C, et al. AOSpine thoracolumbar spine injury classification system: fracture description, neurological status, and key modifiers. Spine (Phila Pa 1976). 2013;38(23):2028-37.

16. Vaccaro AR, Lehman RA Jr., Hurlbert RJ, Anderson PA, Harris M, Hedlund R, et al. A new classification of thoracolumbar injuries: the importance of injury morphology, the integrity of the posterior ligamentous complex, and neurologic status. Spine (Phila Pa 1976). 2005:30(20):2325-33

17. Vaccaro AR, Koerner JD, Radcliff KE, Oner FC, Reinhold M, Schnake KJet al. AOS pine subaxial cervical spine injury classification system. European spine journal : official publication of the Eur Spine J. 2016;25(7):2173-84.

18. Silva OT, Sabba MF, Lira HI, Ghizoni E, Tedeschi H, Patel AA, et al. Evaluation of the reliability and validity of the newer AOSpine subaxial cervical injury classification (C-3 to C-7). J Neurosurg Spine. 2016;25(3):303-8.

19. Yacoub AR, Joaquim AF, Ghizoni $E$, Tedeschi $H$, Patel AA. Evaluation of the safety and reliability of the newly-proposed $A O$ spine injury classification system. J Spinal Cord Med. 2017;40(1):70-5.

20. White AA 3rd, Panjabi MM, Posner I, Edwards WT, Hayes WC. Spinal stability: evaluation and treatment. Inst Course Lect. 1981;30:457-83.

21. Patel AA, Hurlbert RJ, Bono CM, Bessey JT, Yang N, Vaccaro AR. Classification and surgical decision making in acute subaxial cervical spine trauma. Spine (Phila Pa 1976). 2010;35(21 Suppl):S228-34

22. Patel AA, Dailey A, Brodke DS, Daubs M, Harrop J, Whang PG, et al. Thoracolumbar spine trauma classification: the Thoracolumbar Injury Classification and Severity Score system and case examples. J Neurosurg Spine. 2009;10(3):201-6.

23. Joaquim AF, Ghizoni E, Tedeschi H, Lawrence B, Brodke DS, Vaccaro, AR, et al. Upper cervical injuries - a rational approach to guide surgical management. J Spinal Cord Med. 2014;37(2):139-51.

24. Joaquim AF, Ghizoni E, Tedeschi H, Yacoub AR, Brodke DS, Vaccaro AR, et al. Upper cervical injuries: Clinical results using a new treatment algorithm. J Craniovertebr Junction Spine. 2015;6(1):16-20.

25. Anderson LD, D'Alonzo RT. Fractures of the odontoid process of the axis. J Bone Joint Surg Am. 1974;56(8):1663-74. 